\title{
Towards a Theoretical Model for Strategic Alliance, and Partner Selection Among Small Medium Enterprises (SMES): A Research Agenda
}

\author{
Richard Kioko Muthoka, James Kilika \\ Department of Business Administration, Kenyatta University, Nairobi, Kenya \\ Email address: \\ rmuthocah@gmail.com (R. K. Muthoka), kilikam3@yahoo.com (J. Kilika)
}

\section{To cite this article:}

Richard Kioko Muthoka, James Kilika. Towards a Theoretical Model for Strategic Alliance, and Partner Selection Among Small Medium Enterprises (SMES): A Research Agenda. Science Journal of Business and Management. Vol. 4, No. 1, 2016, pp. 1-7. doi: $10.11648 /$ j.sjbm.20160401.11

\begin{abstract}
Partner selection has been identified as a crucial stage in the formation of alliances and critical questions have been raised on the factors that influence different firms during the partner selection process and why a firm will choose one firm and not the other. A multidisciplinary theoretical perspective has been adopted in this paper in an effort to provide insights on how partner selection in alliances can be influence not only by contextual factors but also by top management teams. An integrative perspective is proposed and a conceptual framework suggested showing the link between strategic alliances, contextual factors and top management teams. In conceptualizing these constructs, it is proposed that macro-environmental factors and top management teams mediate the relationship between strategic choice and partner selection.
\end{abstract}

Keywords: Strategic Alliances, Networks, Partner Selection, Macro-environmental, Small Medium Enterprises, Competitive Advantage, Cognition

\section{Introduction}

In the current business context, a heightened awareness of the strategic networks in which firms are situated has become a central, rather than a peripheral theme to understanding firm strategy and performance [9]. Extant strategic management literature and empirical studies have indicated that strategic networks are relevant contingent strategies that firms of all sizes have adopted to deal with environmental pressures posed by the $21^{\text {st }}$ century. The study of strategic networks has also become a useful approach to enhancing our understanding of the sources of firm heterogeneity [9].

One of the emerging concepts in the study of strategic networks is the motives for entering into alliances and partner selection during the process of forming alliances. Empirical literature has indicated that firms enter into alliances for different motives [2] and partner selection is a critical stage that ultimately determines the performance of the alliance [21]. In the study of firm motives under alliances, different scholars have used diverse variables or categories to measure motives for alliance formation resulting to confusion and lack of consistency in what motivates firms to enter into alliances [6]. Even though firms in different industries and markets have different motives for forming alliances, majority of the studies on strategic alliances have focused on developed markets creating a gap for studies in developing as well as emerging markets.

As earlier argued, partner selection in alliance formation is critical and therefore firms involved in alliance formation usually base their partner selection on an analysis and evaluation of the overall strategic fit between the two or more partners [21]. This analysis and evaluation involves strategic thinking and decision making by top management in firms who end up choosing the strategic partner to work with. In addition, several factors come into play during the selection process and these influences the strategic choice of a partner(s). In addition, extant literature and research has indicated that macro-environmental factors of political, economic and social context [12] and the characteristics of the firm, such as size, organizational type, industry and organizational culture can influence this partner selection process. Despite the emphasis on the importance of partner selection among firms, there has been an increase in alliance failures which can partly be attributed to faulty selection processes [21]. One missing link in empirical literature is an 
integrated view of partner selection in alliances that combines the motives for forming alliances, the effects of contextual factors, and top management teams on partner selection.

Majority of empirical studies on strategic alliances have methodological shortcomings especially in their focus on geographical and/or industry resulting to biases and limiting generalization and applicability of their findings [6]. In addition the different organizational challenges experienced in the management of alliances in different contexts limits the extent to which current studies can be generalized [18]. This therefore means that the organizational challenges experienced in alliances in emerging markets will differ from those experienced in developed markets as well as the different types of alliances (domestic firms vs international firms and domestic vs domestic firms). Based on the above arguments, the problem that is emerging is probably the lack of comparable data on partner selection in alliances in emerging markets of Sub Saharan Africa and the compounding effect of the factors that influence the partner selection process.

This paper proposes for an integrated approach to analysing the partner selection process in firms. The Small Medium Enterprise (SME) sector is a critical sector in emerging markets and therefore constitutes a major construct for this paper. To achieve this objective, a review of relevant theories and empirical studies is undertaken to advance the phenomenon of strategic alliances and partner selection. Secondly, relevant constructs are identified in the subject of strategic alliances and partner selection and finally, a theoretical framework is proposed highlighting the relationship between the identified constructs.

\section{Theoretical Review}

This paper adopted a multidisciplinary perspective founded on several theoretical streams. In the context of emerging markets, the contingency theory has been adopted as a base for advancing the necessity of networks as contingent strategies for adapting to environmental turbulence. The theory argues that the survival of organizations depends on how well they adapt to their environments and that organizational structures and strategies are the contingent actions of how organizations respond to changes in their environment [1]. In relation to strategic alliances, the theory presents alliances as new forms of organizational structure that firms adopt as strategies to cope with the environmental pressures they encounter.

The Resource Based View (RBV) advances the concept of competitive advantage by utilizing the firm's resources which can either be intangible or tangible. According to the theory, firms enter into alliances to access resources owned by other firms in the market or industry and such resources have been identified as a source of competitive advantage to network members. The theory also argues that for resources to be shared within an alliance, the alliance members should interrelate through relationships governed by trust.
The transaction theory has argued that a firm's activities have a cost implication and that firms strive to reduce these costs in their activities. The alliance formation process has been adopted by firms to reduce their cost of doing business, for example, reduce the cost of research and development, easy access to knowledge, access to markets and reduce the cost of capital requirements [24]. The theory assumes that the risk of opportunism is inherent in many transactions [26] and in strategic alliances; opportunism is a major pitfall in many strategic alliances. The theory is used to advance the argument that top management teams make strategic choices that have consequences to the firm, in this case, the strategic partner selection during alliance formation. Secondly, the theory is used to support the argument that alliances expose alliance members to certain benefits and pitfall.

The institutional theory has been adopted to further the argument on the motivating factors for entering into strategic alliances since the theory emphasizes the influence of the systems surrounding organizations and advocates for individual level analysis when studying institutions. This theory has contributed in strengthening the argument that incorporating top management teams in the study of partner selection in alliances can show their contribution to partner selection how that role impacts on the effectiveness of alliances in achieving competitive advantage. However, the theory does not adequately provide for how to undertake individual analysis in the study of the firm.

Together the theoretical streams complement each other in advancing the concept of strategic alliances and partner selection in SMEs. The contingent theory captures the phenomenon of strategic alliances as a relevant strategy for SMEs to adapt to environmental pressures while the RBV and the transaction theory illustrates the motives for entering into alliances by SMEs and the relevance of strategic alliance among alliance members. The institution theory and the cognition theory complement in that the institution theory argues that for a full understanding of firm behaviour individual analysis is required but the theory fails to highlight how to undertake this analysis. This shortfall can be complemented by the cognition theory which advances individual analysis from a psychological perspective. In totality, the theories studied add specific value to advancing the phenomenon of strategic alliances, in particular motives for forming alliances, the importance of partner selection during alliance formation and how decision making by individuals within the firm impact on the partner selection process and therefore, should not be used in isolation but in combination [7].

An analysis of some of the empirical attempts reveals that firms have multiple motives for enacting alliances and partners in alliances often have similar or different motives for entering into alliances [16]. In addition, these motives differ according to the industry the SME is operating in and the specific type of alliance to be formed [7]. The empirical analysis has also shown that financial assets, technological capabilities, intangible assets and willingness to share expertise are more important in the selection of alliance 
partners in emerging markets than developed markets.

From the extant empirical review, it is evident that there is a lack of consistency in researches that look at the motives for alliance formation as different scholars have used diverse variables to measure the motives for partner selection. In addition, partner selection criteria or variable have also differed in most studies resulting to inconsistency in relevance and limiting comparison among the studies. [6] recommends that there is need to adapt already existing selection criterion as this can help in comparing different studies and the same author has identified a broad categorization of selection criteria by distinguishing the selection criteria based on operational skills (task related criteria) and resources requirements (partner-related criteria). [6] Noted that most of the studies on strategic networks suffer from potentially serious methodological shortcomings and cites geographical or industrial focus as biases in such studies which in addition limit the generalization and applicability of their results. According to [18] organizational problems are of a different character in the management of alliances in different contexts (emerging/developed markets, international/domestic alliances) and therefore this creates the need to undertake studies in different contexts to enrich the existing literature and knowledge on the subject.

From the review of the extant empirical literature, the researchers have raised several suggestions; first there is need to adopt an integrated perspective when studying partner selection in alliances among SMEs. This perspective should highlight the relationship between contextual factors of the macro-environment in emerging markets and top management teams in SMEs and how contextual factors influence partner selection during alliance formation. Secondly, empirical studies need to establish the relationship between contextual factors of competition, regulation, macroeconomic factors and technology in emerging markets and strategic choice (partner selected) undertaken by top management teams in SMEs. Thirdly, empirical studies need to establish the relationship between contextual factors of political/legal, economic factors of inflation and exchange rate in emerging markets and the motives for alliance creation by SMEs operating in these markets. Fourthly, empirical studies need to establish the mediating effect of partner selection in the relationship between strategic alliances and competitive advantage. Lastly, there is need to establish the moderating effect of top management teams in the relationship between strategic alliances and partner selection and partner selection and competitive advantage.

Thus the conceptualization of the construct of strategic alliance as an aspect of firm strategic behaviour needs consideration so as to explain the emergent phenomenon leading to firm competitive advantage.

\subsection{Conceptualization of the Construct of Strategic Alliance}

The attempts by strategists to understand the phenomenon involving strategic alliances has paid attention to the nature of alliances, the type of alliances and the motives for entering into alliances. According to [11] strategic alliances are longterm partnership relationships developed between several legally and formally independent organizations for purposes of long-term strategic cooperation. [14] Indicated that strategic alliances among firms are mainly of two forms: (1) equity alliances where each partner owns a percentage of the equity in a venture that the firms have jointly formed for example joint ventures, and mergers and acquisition (2) nonequity alliances which are contractual agreements between two or more firms in which each partner agrees to share some of its resources or capabilities and examples include; Research and Development alliances, franchising, licencing, supplier partnerships, marketing agreements, and joint production. Strategic networks are characterised by a set of relationships composed of inter organizational ties that are enduring and of strategic significance and interdependence among network members who share resources and information, technology and access to markets.

Extant literature outlines several motives why firms enter into strategic alliances and this study adopts the motives as outlined by [2] to include; (1) transaction-cost motives where firms aim to reduce the cost of conducting business through alliances; (2) resource-based motives where firms seek to access resources that are lacking in their firms from alliance member(s); (3) strategic motivations which entails formatting alliances to gain a more competitive position in the industry; (4) learning objectives where firms are seeking to gain information or knowledge from the alliance, for example, learn about a new technology; and (5) motives relating to reducing the risk of doing business, for example, when firms are entering into new markets and would like to distribute the associated risks by forming partnerships with other firms in the industry. Strategic alliances offer four kinds of benefits namely; (1) economies of scale and economies of scope; (2) quick and easy access to knowledge and markets; (3) the reduction of the capital requirements and the risks involved in the development of new kinds of products or technologies; and (4) the possibility of influencing the structure of competition in the relevant markets [24].

From this point of motives, it is evident that the strategic process of adopting network or alliance as a corporate strategy approach calls for strategic thinking and decision making. Organizations entering into strategic alliances approach the choice to enter or not to enter into an alliance, the selection of appropriate partners to cooperate with and the structure for the alliance as a strategic decision [8]. Since strategic decisions require a consideration of the external environment, the external context of the firm entering into an alliance needs consideration.

\subsection{Strategic Alliances Among Small Medium Enterprises (SMEs)}

According to [23], Small Medium Enterprises (SMEs) are defined as non-subsidiary, independent firms which employ between 200 and 500 employees. The resulting complexity and dynamic nature of markets in the context of emerging markets and globalization has intensified the need for 
businesses to develop the ability to create unique sets of resources in order to ensure sustainable corporate success. One of the strategies that can be used to manage this situation especially for SMEs is to enter into cooperative relationships or networks [5]. The [23] policy paper recommended that Governments need to improve SME access to financing, information infrastructures and international markets through providing regulatory, legal and financial frameworks conducive to SME start-up and growth, fostering publicprivate partnerships and small-firm networks and clusters. These are components of the firm's macro-environment. The macro-environment is recognized in strategic management for its role in availing both business opportunities and threats that strategists should address.

\subsection{Macro-environmental Factors}

The emerging markets have been characterized as challenging for the firm conducting business in them because; (1) increased uncertainty and risk resulting from both economic and political shocks, (2) Domestic policies are becoming more market-oriented and (3) Institutional arrangements are 'weak' [13]. The compounding effects of the economic shocks in emerging markets do influence partner selection decisions since partner selection is influenced by a firm's behaviour which is nested, or embedded in broader macro-environmental factors [12].

\section{Proposed Theoretical Framework}

This proposed conceptual framework provides propositions to offer alternative approaches to fill the identified gaps in extant empirical review. The extant literature reviewed indicated that partner selection in alliance formation can significantly influence the success of a firm and that firms in emerging markets possess different motivations for entering into alliances. Strategic thinking and decision making were identified as key components in partner selection and therefore top management plays a crucial role in making decisions regarding partner selection and contextual factors greatly influence this decision making process. The conceptual framework illustrates the interaction of this variable.

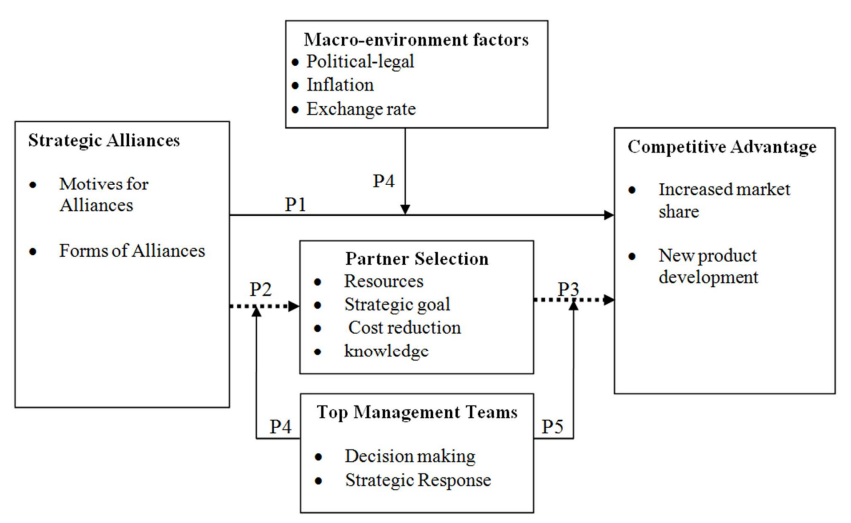

Figure 1. Proposed Theoretical Model.
Figure 1 above outlines a graphical representation of the propositions advanced to show the relationship among the major constructs in the phenomenon of strategic alliance. The section that follows discusses the relationship between the phenomenon of strategic alliance and competitive advantage and how partner selection in alliance formation mediates that relationship. The constructs of macro-environmental factors and strategic orientation have been presented as moderators of the relationship between strategic alliances and the partner selection process in alliance formation.

\subsection{Formation of Strategic Alliances}

The numerous environmental shocks experienced in emerging markets [10], necessitate the formation of alliances as a contingent strategy among SMEs in this markets. As a result, these SMEs are in a position to overcome resource shortages, reduce transaction costs and reduce information search costs [19]. Extant theoretical literature reviewed indicated that inter-organizational relationship is a major characteristic in networks [9]. The Resource Based View of the firm argues that the resources embedded in networks are accessible to network members and this can be a source of competitive advantage. Thus,

Proposition 1: the firms that acquire valuable resources through strategic alliance will in turn gain competitive advantage

\subsection{Strategic Alliance and Partner Selection}

The partner selection process has been identified as challenging as a result of difficulty in obtaining information regarding the competencies and needs of potential network partners and the scarcity of information about the reliability of the potential partners [8]. In addition, firms in emerging markets are faced with the challenges of lacking a welldefined property rights that convey exclusivity, transferability, and quality of title [4] and weak institutional arrangements that result to high transaction costs, information asymmetries [20] and high costs for searching for information [25]. These challenges have been aligned with the emergence of opportunistic behaviour among alliance partners which can in turn cause poor performance of the alliance [21]. One of the preventive mechanisms of minimizing opportunistic behaviour in alliance is through embracing a governance structure that incorporates contractual agreements [19]. Faced by the challenges of emerging markets, SMEs will have different motives for entering into alliances including; transaction-cost motives, resource-based motives strategic motives, learning objectives and motives relating to risk reduction [2].

In theory, there are two basic forms of strategic alliances, that is, equity alliances and non-equity alliances [3]. Equity alliances have been defined as alliances where both partners have equity or capital contribution into the venture and examples can include joint venture, merger and acquisition. On the other hand, non-equity alliances are contractual agreements between two or more firms in which each partner 
agrees to share some of its resources or capabilities [14]. A study by [7] found that a combination of firm, environmental and partner-related motives stimulate SMEs to opt for a specific type of strategic alliance and suggested the need to assess where motives will differ for alliance types in which equity alliances are formed versus non-equity alliances. Therefore:

Proposition 2: The firm motive and type of alliance sought will determine the selection of the strategic partner with whom to enter into alliance.

\subsection{Partner Selection and Competitive Advantage}

The alliance partner selection stage in alliance formation involves the choice of a partner or group of partners with which a firm seeks to realize its objectives. According to [6] the choice of a particular partner is an important variable influencing alliance performances, the mix of skills and resources which will be available to the alliance and the ability to achieve its strategic objectives and behaviour of the network partners [21]. This paper adopts [6] partner selection criteria in alliances which distinguishes partner selection into two broad categories of task-related criteria and partnerrelated criteria. Task-related criteria refer to those variables which are closely related to the success of the venture and include variables such as patents and technical knowhow, financial resources, skilled and experienced management and access to markets. On the other hand partner-related criteria refers to those variable that are important when forming alliances with several partners and such variable include corporate culture, compatibility of trust between management teams and the partner's size.

Proposition 3: The strength of the relationship between strategic alliances and competitive advantage will to a great extent depend on the strategic partner selection process by a firm.

\subsection{Macro Environmental Factors}

The macroeconomic environment in emerging markets has been characterised as dynamic and complex thus exposing the firm in these markets to strong environmental pressures for change since this exposes strategic alliances to organizational problems [18]. These environmental pressures in turn influence the overall performance of strategic alliances in achieving competitive advantage. Therefore:

Proposition 4: The state of macro environmental factors in emerging markets moderate the relationship between strategic alliances and competitive advantage.

\subsection{Top Management Teams, Partner Selection and Competitive Advantage}

According to [22], one of the subjective representations used by top management in decision making with regard to the external environment is attention and focus which has been defined as, 'the degree to which top managers' subjective representations of their external environment are dominated by concepts related to one (or more) domain over others subjective representations that top managers develop about their environment" [22]. This paper adopts [22] argument that external variables of competition, regulations, macroeconomic factors and technology affect top management's attention and focus during decision making. The same author argues that focusing on specific environmental event increases the likelihood of including such events in a firm's strategic agenda and will ultimately influence strategic choice.

Strategic alliances pose some risks of opportunistic behaviour from network partners or network members' [17]. After the implementation of strategic alliances as strategic choices, top management teams are involved in monitoring, evaluation and control of the implementation process of strategy [15]. This monitoring, evaluation and control entails amending any deviations from the intent objectives of choosing the strategy at hand. In cases of strategic alliances, opportunistic behaviours might not be identifiable at the partner selection stage which therefore necessitates the need to evaluate and control the strategic alliances at the alliance management stage. In situations where top management teams identify symptoms of opportunistic behaviour, the necessary corrective action should be undertaken since this can negatively impact on the effectiveness of strategic alliances in directing the firms towards competitive advantage.

Since the partner selection process is identified is a strategic choice, it can be concluded that partner selection will be affected by external variable of competition, regulation, macro-economic and technology as these variables have a significant influence on top management attention and focus during strategic thinking and decision making. It can also be concluded that top management teams have the responsibility to evaluate and control strategic alliances to main their effectiveness at gaining competitive advantage. Therefore since Top management teams in SMEs will consider contextual factors of competition, regulation, macro-economic and technology when selecting potential alliance partner(s), it is proposed that:

Proposition 5: The SME TMT Decision making will moderate the relationship between strategic alliance option and the partner selection process

Given that the Top management teams in SMEs will consider opportunism in alliance management to assess effectiveness of the alliance in achieving their strategic goals, such a move will influence the firms overall performance. Thus,

Proposition 6: The SME TMT strategic response will moderate the relationship between partner selection process and competitive advantage

\section{Conclusion}

The purpose of this theoretical paper was to review both extant theoretical and empirical literature, identify existing gaps in the phenomenon of partner selection in strategic alliances and finally suggest a theoretical framework 
providing propositions for filling up the identified gaps. The theoretical paper is anchored in the concept of strategic alliances and a critical review of the process of partner selection was undertaken with a special focus on Small Medium Enterprises (SMEs). Extant literature reviewed has identified the alliance formation process as constituting of specific stages and the partner selection stage has been recognized as a key determinant to the overall performance of the alliance and achievement of competitive advantage as well. The undertaken review of extant empirical literature indicated that the integration of contextual factors and top management teams are a missing link in studying the partner selection especially for SMEs in emerging markets. This paper adopted a multidisciplinary based approach to propose an integrated theoretical model for explaining the partner selection process in strategic alliance process to attain competitive advantage.

While this paper contributes to the literature on partner selection in a number of ways, it also makes suggestions for future research. First, the paper identifies the weaknesses in existing empirical literature and provides an integrated perspective of enhancing the current understanding of the phenomenon of strategic alliances particularly the process of partner selection in SMEs and secondly the paper contributes by providing propositions on how to enrich existing literature in the concept of strategic alliances especially in emerging markets. Thirdly, the paper pin points a possible direction for further research in the area of strategic alliances that strategic management scholars can consider and the researchers believe this will contribute towards harmonizing the existing discrepancies in the study of strategic alliances. In view of these identified weaknesses, the paper suggests that future research embrace these integrated theoretical model to guide empirical work in less studied context for SMEs as those of developing and emerging markets. Future research can also focus on multi-industry firms to provide an in depth understanding of strategic alliances across diverse industries and allow comparisons among these industries.

\section{References}

[1] Alexander, E., R. (2013). How organizations act together: Inter-organizational Coordination in Theory and Practice. New York; Routledge Taylor \& Francis Group.

[2] Child, J., Faulkner, D. \& Tallman, S. B. (2005). Cooperative Strategy: Managing Alliances, Networks, and Joint Ventures. Oxford University Press, Oxford.

[3] Culpan, R. (2002). Global Business Alliances: Theory and Practice. USA; Quorum Books.

[4] Devlin, R. A., Grafton, R. Q., \& Rowlands, D. (1998). Rights and Wrongs: A property rights perspective of Russia's market reforms. Antitrust Bulletin. 43.

[5] Fink, M., \& Kessler, A., (2010). Cooperation, Trust and Performance - Empirical Results from Three Countries. British Journal of Management. 21.
[6] Geringer, J., M. (1991). Strategic Determinants of Partner Selection Criteria in International Joint Ventures. Journal of International Business Studies. 22(1).

[7] Gils, A., V. \& Zwart, P., S. (2009). Alliance Motives in SMES. An Explorative Conjoint Analysis Study. International Small Business Journal. 27(1).

[8] Gulati, R. (1995). Social structure and alliance formation patterns: a longitudinal analysis. Administrative Science Quarterly. 40.

[9] Gulati, R., Nohria, N., \& Zaheer A. (2000). Strategic Networks. Strategic Management Journal. 21(3).

[10] Hermelo, F., D., Hetiennot, H., \& Vassolo, R., S. (2014). "Sources of performance heterogeneity in emerging economies", The Journal of the Iberoamerican Academy of Management, 12 (2)

[11] Hinterhuber, H., H., \& Hirsch, A. (1998). Starting Up a Strategic Network. Thunderbird International Business Review. 40(3).

[12] Hitt, M., A., Dacin, M., T., Levitas, E., Arregle., J. \& Borza, A. (2000). Partner Selection in Emerging and Developed Market Contexts: Resource-Based and Organizational Learning Perspectives. The Academy of Management Journal. 43(3).

[13] Hoskisson, R., E., Eden, L., Lau, C. M., Wright, M. (2000). Strategy in emerging Economies. Academy of Management Journal. 3(3).

[14] Ireland, R., D., Hoskisson, R., E., \& Hitt, M., A. (2009) 2009). Understanding Business strategy: Concept and cases. 2Ed. USA; South-Western.

[15] John, R., Cox, H., Let to-Gillies, G., Grimwade, N., Allen, M., \& Finn, E. (1997). Global Business Strategy, London, Thomson.

[16] Klijn, E. Reuer, J., J. Buckley, P., J. Glaister, K., W. (2010). Combinations of partners' joint venture formation motives. European Business Review. 22(6).

[17] Kogut, B. (1988). Joint ventures: Theoretical and empirical perspectives. Strategic Management Journal. 9.

[18] Llaneza, A., V., \& García-Canal, E. (1998). Distinctive Features of Domestic and International Joint Ventures. Management International Review. 38(1).

[19] Luo, Y. (2002). Capability exploitation and building in a foreign market: implications for multinational enterprises. Organization Science. 13(1).

[20] Meyer, K., E. (2001). Institutions, transaction costs and entry mode choice. Journal of International Business Studies. 31.

[21] Moeller, K. (2010). Partner selection, partner behaviour, and business network performance: An empirical study on German business networks. Journal of Accounting \& Organizational Change. 6(1).

[22] Nadkarni, S., \& Barr, P., S. (2008). Environmental Context, Managerial Cognition, and Strategic Action: An Integrated View. Strategic Management Journal. 29(13).

[23] Organization for Economic Co-operation and Development (OECD). (2000). Small and Medium-sized Enterprises: Local Strength, Global Reach. Policy Brief. 
[24] Schmidt, R., H. \& Fellermann, S. (1993). On Explaining Strategic Alliances. Journal of Institutional and Theoretical Economics. 149(4).

[25] Tong T., W., Reuer J., J., Peng M., W. (2008). International joint ventures and the value of growth options. Academy of Management Journal. 51(5).
[26] Williamson, O., E., (1985). The economic institutions of Capitalism. New York; Free Press. 